\title{
Arbor
}

\section{Don Juan de Dios de la Rada y Delgado y los expedicionarios de la fragata de guerra Arapiles en Tierra Santa}

\section{José Pascual González}

Arbor CLXXX, 711-712 (Marzo-Abril 2005), 805-824 pp.

En el verano de 1871 el Gobierno de Amadeo I de Saboya envió a los mares del Mediterráneo oriental a la fragata de guerra Arapiles, a bordo de la cual embarcó una comisión científica que tenía la misión de obtener piezas procedentes de la zona para el Museo Arqueológico Nacional. El presente trabajo analiza la estancia de los expedicionarios en Tierra Santa y, a través de la obra del presidente de dicha Comisión, D. Juan de Dios de la Rada y Delgado, profundiza en su mentalidad y en las impresiones que causaba el Oriente en los viajeros occidentales de entonces.

En aquel entonces corría la canícula de 1871 y alboreaban los primeros meses del reinado, a la postre efímero, de Amadeo I de Saboya ${ }^{1}$, cuando el Gobierno de S.M. despachó a los mares del Levante la fragata blindada Arapiles.

Aunque los motivos de la expedición, por R.O. de 10 de junio de 1871, fueron eminentemente políticos y patrióticos y vagamente comerciales ${ }^{2}$, en el sentido de hacer visible la presencia española en Oriente, mostrando la enseña nacional, y de valorar las posibilidades de intercambio mercantil con el Mediterráneo oriental, a través de la firma de diversos tratados internacionales; a bordo de la Arapiles embarcó también una 
Comisión científica que tenía como finalidad dotar al entonces recién fundado Museo Arqueológico Nacional (1867) de piezas procedentes de dicha zona.

Dicha Comisión, nombrada el 13 de junio de 1871, estaba compuesta por tres miembros: D. Juan de Dios de la Rada y Delgado ${ }^{3}$, presidente de la Comisión y que habría de escribir una voluminosa obra sobre el viaje ${ }^{4}$, D. Jorge Zammit y Romero, secretario de embajada, en calidad de intérprete, por la gran cantidad de lenguas que dominaba ${ }^{5}$, y D. Ricardo Velázquez y Bosco, académico de la Real de San Fernando, como dibujante y fotógrafo ${ }^{6}$. Los comisionados partieron de Madrid por tren camino de Nápoles, donde estaba entonces atracada la fragata, ya que había asistido a la Exposición Marítima, que se había celebrado en dicha ciudad y a la que llegan el día 6 de julio.

Uno de los primeros y más graves problemas al tuvieron que hacer frente los miembros de la Comisión fue la penuria de medios económicos. Para sus dispendios se libró la suma de 2.500 pesetas, extraídas del fondo de 50.000 pesetas que tenía el Ministerio de Fomento para obras y adquisición de objetos del MAN7 ${ }^{7}$. Con esos magros fondos no sólo se debían pagar las dietas de los miembros de la Comisión (quince pesetas diarias para Rada, otras tantas para Zammit y diez pesetas para Velázquez) sino también los demás gastos, compras de objetos incluidas. Sólo las dietas, en los ochenta y seis días que duró el viaje, ascendían a 3.440 pesetas, por lo que no se puede hablar en realidad sensu stricto de una partida para la adquisición de piezas.

Como era previsible, muy pronto se quedaron sin dinero. El 27 de julio, a las tres semanas del comienzo del viaje, el Comandante de la fragata, D. Ignacio García de Tudela, ha prestado a los comisionados mil francos de la Caja del barco, unas novecientas cincuenta pesetas ${ }^{8}$; el 12 de agosto dicha cantidad había ascendido ya a tres mil francos. A menos de un mes de la partida, en el barrio de Pera, en Constantinopla, los miembros de la Comisión envían sendos telegramas en demanda de fondos, a D. Sergio Sálvez, habilitador del MAN (4/VIII/1871), y al propio Director, D. Ventura Ruiz Aguilera (5/VIII), el dirigido al Director es llamativamente dramático: «fondos cero ayúdenos Ministro con su legítima influencian. Sus solicitudes jamás fueron consideradas ${ }^{9}$. Esta escasez de medios económicos hizo prácticamente imposible toda compra y obligó, incluso, a recortar la estancia en cada puerto ${ }^{10}$.

Dicho de una manera breve, en la expedición concurrieron objetivos muy diversos, insuficiencia de recursos económicos y escasez de tiempo, elementos que nunca deben dejarse de lado a la hora de valorar sus re- 
sultados. De hecho, en rigor, no puede esperarse poco más que un viaje de exploratorio.

La fragata salió de Nápoles en la madrugada del 7 de julio de 1871. Antes de su llegada a Tierra Santa tocó los puertos de Nápoles, Mesina, Siracusa, El Pireo, Besika, Constantinopla, Esmirna, Quíos, Samos, Rodas, Lárnaca y Beirut.

Centrémonos en la estancia en Tierra Santa. La Arapiles arribó al puerto de Jafa, procedente de Beirut, con el crepúsculo del 30 de agosto de 1871, aquí habría de permanecer anclada hasta el 3 de septiembre, con el fin de que los miembros de la comisión y una pequeña parte de la dotación visitasen Jerusalén y Belén.

Durante la travesía de Beirut a Jafa, con la vista puesta en el rectilíneo litoral palestino por la banda de babor, Rada principia su relato sobre Tierra Santa: "Henos aqui ya delante de palestina, aquella comarca tan llena de recuerdos para el historiador, para el arqueólogo, para el artista y sobre todo para el cristiano" (Viaje a Oriente, III, 67). Si a lo largo de su obra, Rada vuelve, una y otra vez, sobre el Cristianismo católico, que forma parte consubstancial de su pensamiento; en Tierra Santa este catolicismo se torna especialmente vivo y marcará profundamente su estancia. En estos días el estudioso, el científico, el erudito, el arqueólogo, aunque sin olvidarse de ello, cede ante el creyente, de modo que, su estadía en Tierra Santa es, fundamentalmente, la de un peregrino al que la fe condiciona, cuando no determina, no sólo su relato sino también las opciones sobre los lugares que han de visitarse y estudiarse.

Rada procede después de una manera sistemática, describe la geografía palestina, especula sobre su nombre que "se cree que provenga de los Philistinos y la tierra de Cham o Cannam» (III, 67-68) y pasa a definir las grandes etapas de la historia de Canaam: los patriarcas, de Abraham a Moisés; desde la salida de Egipto y el establecimiento de la Monarquía; la época de la Monarquía; el cisma de la separación entre Israel y Judá hasta la Cautividad de Babilonia en 606 y, por último, desde Nabuconodosor a Adriano (III, 68-69). Al narrar el período monárquico, Rada señala, como uno de sus elementos definitorios, que «el genio comercial de los judios, estimulado por sus relaciones con los fenicios, presentaba cada vez más dilatados horizontes de engrandecimiento y prosperidad" (III, 69). Este pequeño comentario acerca de las relaciones establecidas entre fenicios y hebreos en época de Salomón, puede servir muy bien para introducirnos en otro aspecto esencial del pensamiento de Rada, el liberalismo. Ya al principio de su obra ha afirmado la doctrina liberal con la importancia del ahorro y del capital y así «con la moneda el hombre conoció el 
ahorro, $y$ con el ahorro el capital; $y$ con el capital la poderosa palanca de la actividad humana, en todas sus manifestaciones" (I, 10), insiste también en el liberalismo siempre a lo largo de su estancia en Palestina y en las propias conclusiones de su obra «manifestando nuestra creencia de que nuestro porvenir es en Oriente; que debemos esforzarnos por dirigir hacia alli nuestro comercio, favoreciendo los cambios de producciones con liberales reglamentos, y quitando trabas a la navegacion» (III, 222) ${ }^{11}$. Es necesario apuntar que el pensamiento liberal de Rada alcanza esencialmente a su vertiente económica; así, reconoce la importancia del ahorro, del capital y del trabajo que deben aunarse en la producción de manufacturas de buena calidad y a buen precio (III, 221-222); todo lo cual necesita, además, de medidas de corte liberal y hasta librecambista como son la reforma de todos los reglamentos y muy especialmente un decidido impulso a la libertad de navegación. En el estado atrasado de la España de la época, su liberalismo hace hincapié más en el auge del comercio que en la industrialización, defiende la necesidad del comercio como elemento esencial y dinamizador de la riqueza y propugna encendidamente que España establezca amplias relaciones comerciales el Levante lo que favorecerá, finalmente, la industria. En su concepción económica liberal, Rada se muestra avanzado con relación a las tendencias proteccionistas que respaldaban los sectores conservadores coetáneos.

Nuestro viajero sigue narrando la división provincial romana de $\mathrm{Pa}$ lestina de la época de Diocleciano y la dominación árabe, a partir de 636, trata los cruzados brevemente, y llega a la época turca. En 1871 Tierra Santa constituía la provincia de Jerusalén, en el eyalato de Damasco.

Jafa era entonces el puerto al que arribaban los peregrinos que se dirigían a visitar los Santos Lugares, contaba con unos seis mil habitantes y era un espejo de la diversidad que, con diferencias en cuanto al porcentaje en cada lugar, caracterizabâ a Palestina: las dos terceras partes eran musulmanes y el tercio restante estaba formado por una mezcla de griegos, latinos, hebreos, unos cuatrocientos, y algunos maronitas y protestantes.

Tras atracar en el muelle de Jafa, el Vicecónsul de España en la ciudad, un judío sefardí que hablaba un español anticuado (III, 79) acude a bordo para recibir a los expedicionarios. El Vicecónsul ha organizado ya el viaje a Jerusalén y les acompañará. A pesar de la situación retardada de España y de los nulos contactos entre el Oriente y la Península, y si bien mal pagados y, a veces, en misérrimas condiciones en llamativo contraste con sus colegas europeos, una de la características observable a lo largo del viaje de la Arapiles es la red consular, verdaderamente notable, con que contaba el servicio exterior español. 
Don Juan de Dios de la Rada y Delgado y lo expedicionarios...

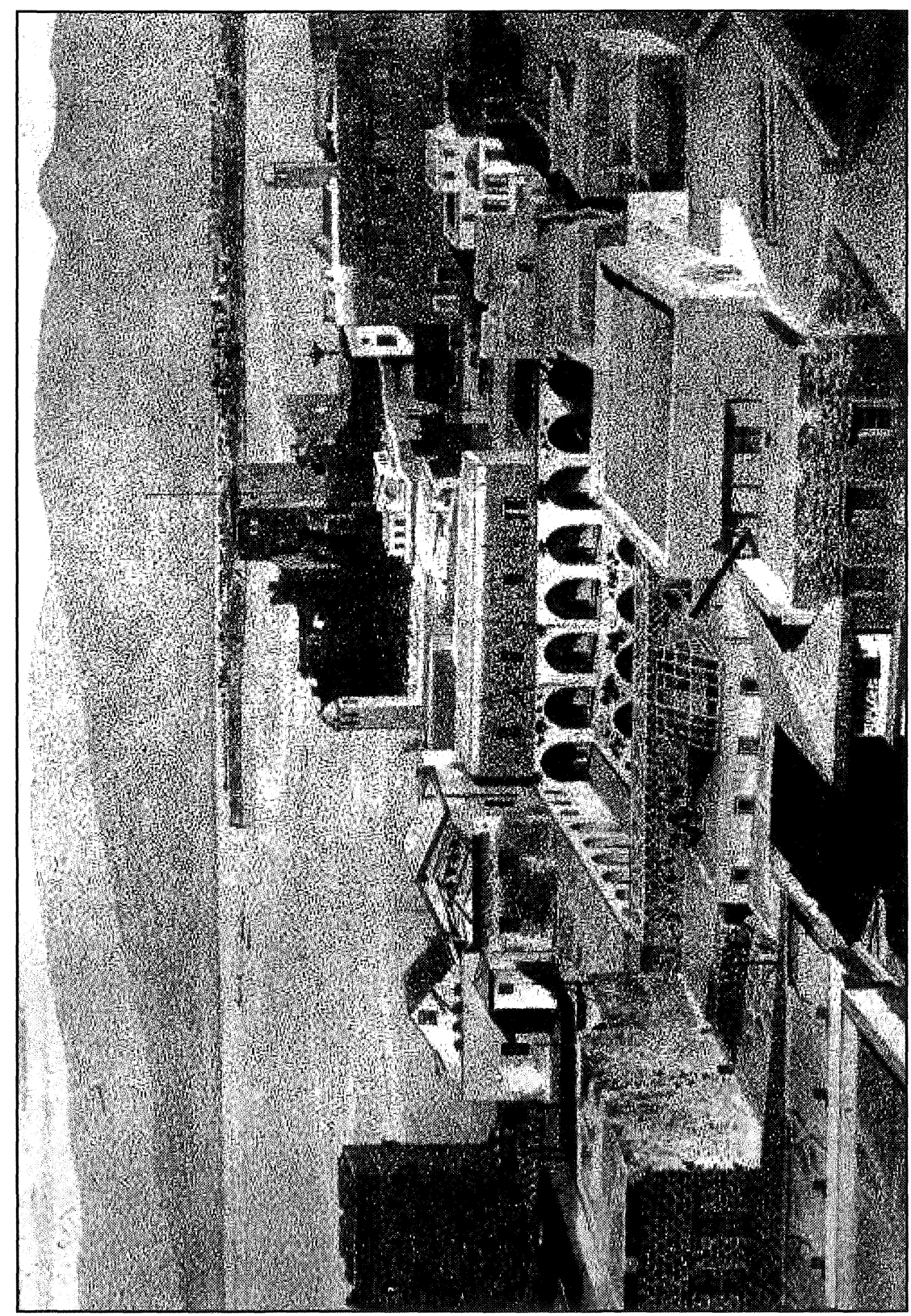

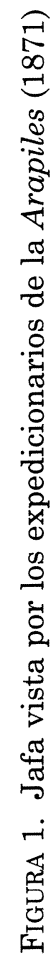


Jafa es motivo para Rada de exótica descripción pintoresquista: «edificada sobre una colina avanza hacia el mar y parece proteger una ruinosa ciudadela con algunos antiguos cañones y restos de almenados muros, como la mayor parte de las poblaciones del imperio turco, tan pintoresca apariencia, a que contribuyen las cupulitas que tienen casi todas su casas y al estar agrupada en anfiteatro, oculta calles miserables y sucias, si bien sus alrededores están cubiertos de frondosos huertos y jardines que justifican su antigua denominación (Joppe: hermosa)》 (III, 70). Rada refiere luego su historia, sus facilidades portuarias y los productos que exportaba (sésamo, trigo, algodón, y naranjas). A pesar de su pobre aspecto contaba con una estación telegráfica, con vapores correo regulares con Occidente, $\mathrm{y}$, en el marco nuevamente de su pensamiento liberal, nos dice que Jafa «daba indicios de entrar en vías de adelantos y engrandecimiento y el comercio empieza a dejar sentir en ella su benéfico influjo» (III, 73) ${ }^{12}$.

Como en la práctica totalidad de los lugares que visitan, Rada y el resto de los expedicionarios contrastan el aspecto externo y encantador de las ciudades del Oriente con su suciedad y nos devuelven la sensación de agobio, con sus callejuelas empinadas, estrechas y sinuosas, que el urbanismo árabe produce en los occidentales ${ }^{13}$. En Jafa, los expedicionarios son recibidos en el convento de San Juan de los Franciscanos que, como todos en Tierra Santa, tiene la doble misión de evangelizar el país y de hospedar a los peregrinos.

Los expedicionarios parten a caballo de Jafa a las tres tarde del día 30 de agosto de 1871 guiados por el Vicecónsul español; el grupo está compuesto por quince personas entre los que figuran los tres de la Comisión, el capellán de la fragata, el Comandante y su mujer, $D^{a}$ Fernandina Casariego, que había embarcado en mayo en Barcelona. El resto lo forman miembros de la tripulación, quizá en buena parte oficiales, que sirven de escolta y protección ya que los expedicionarios temen a los salteadores, principalmente beduinos, y a las fieras salvajes ${ }^{14}$. Su intención es recorrer las quince leguas que separan Jafa de Jerusalén (III, 74), unos 83,5 kilómetros $^{15}$, en poco más de un día y medio. La mayor parte del trayecto se realiza de noche con el fin para evitar el calor del verano palestino y de aprovechar la luz diurna en los sitios que han de visitarse.

Atraviesan la llanura de Sarón, alabando la belleza de las huertas y de campos de frutales especialmente naranjos y granados que se encuentran a su paso (Tudela, 1873, 38). Superan la llamada Casa de Tabita (III, $75)^{16}$, dejan a la izquierda la aldea de Yazar y, poco después, alcanzan un pozo llamado la Fuente del Plátano, no lejos del camino que va a Gaza (III, 76). De acuerdo con Rada, desde la misma fuente parten los dos caminos 
Don Juan de Dios de la Rada y Delgado y lo expedicionarios...

que llevan a Jerusalén, uno a través Lydda, la actual Lod, en el norte, y otro por Ramla hacia el sur. Nuestro grupo elige el camino de Ramla que corresponde aproximadamente a la actual carretera nacional $\mathrm{n}^{0} 44$ que parte de Jafa y luego toma, en las afueras de Ramla, la ruta $\mathrm{n}^{\circ} 424$, que se une, finalmente, a la autopista $\mathrm{n}^{0} 1$ a la altura de Emaús-Nicópolis.

Tras pasar la aldea musulmana de Sarfand, a una media hora de Ramla, que, según-Rada, es la antigua Geth o Geath, «patria de Goliath, aunque también se dice que estuvo en un hermoso pueblo de la extremidad de la llanura de Sarón» (III, 76) ${ }^{17}$, llegan, a la nueve de la noche, después de seis horas de trayecto, a Ramla o Ramatha, de acuerdo con Rada, la antigua Arimatea (III, 76) ${ }^{18}$.

Ramla o Ramleh, pobre y sucia, contaba entonces con cuatro mil habitantes de los que únicamente sesenta eran católicos. Aquí descansaron durante tres horas en el convento de los Franciscanos, donde cenaron y visitaron la iglesia y la capilla de San Nicodemo. En este convento el Padre superior y otros dos monjes eran españoles y el resto italianos: «el $\mathrm{Pa}$ dre Superior nos enseñó la iglesia, que ofrece poco de notable al artista y al arqueólogo, y en ella vimos con placer diferentes ornamentos que procedían de España y estaban marcados con el escudo nacional» (III, 77). Como en otros lugares, Rada no deja nunca de dar muestras de patriotismo señalando los recuerdos de la patria que se van encontrando por el camino, por nimios que éstos sean. Ahora bien, a pesar de su patriotismo, Rada y el resto de los expedicionarios son plenamente conscientes del atraso de España, y proponen siempre soluciones cuales son el comercio con el Oriente, siguiendo el ejemplo italiano, dejando de lado los intercambios poco productivos con Cuba y las Filipinas y, como ya tuvimos ocasión de considerar, el desarrollo económico en sentido liberal.

A medianoche salen de Ramleh, quedarán por delante más de ocho horas para recorrer los sesenta y dos kilómetros que les separan de la Ciudad Santa. A lo largo de estas horas, Rada comienza a experimentar un fuerte sentimiento cristiano, mostrando también, como era propio de la época, un amplio conocimiento de la Biblia. De esta manera, Rada va "evocando los recuerdos que a cada momento despiertan aquellos parajes en la memoria de los que tenemos la fortuna de haber nacido y de vivir en la comunión de Jesucristo» (III, 79). Atraviesan la aldea musulmana de El-Kubab que, según Rada, se cree ocupaba el sitio de la antigua Cobe del Talmud, en los límites de Israel y los filisteos ${ }^{19}$; avistan, al este, al pie de la montaña, la aldea de Beit-Nuba ${ }^{20}$, la antigua Nobe, y se llegan luego a Latrún, la acrópolis de la antigua Emaús-Nicópolis, donde Rada nos indica que «Bien hubiéramos querido visitar en Latrun los restos de una 


\section{José Pascual González}

antigua iglesia, cuya construcción data de los primeros siglos del cristianismo [...], pero la noche y la rapidez de nuestra marcha nos lo impedian" (III, 79) ${ }^{21}$. Aquí, como en otras muchas oçasiones, Rada se refiere al escasísimo tiempo con que cuentan para explorar cada sitio lo que apenas permite otra cosa que señalarlo.

En Latrún, dejan atrás la llanura de Sảrón y se internan en las montañas de Judea en la región conocida como Shephelah. "Más allá de Latrun el camino continuaba por un valle que en el silencio noche resonaba gratamente con el apacible murmullo de un arroyo, y nuestro bondadoso guía nos enseñó el que llaman pozo de donde nunca falta el agua, aunque no siempre clara. Nuevas torres de guardia pueden tranquilizar al viajero en esto valle, y continuando la marcha encontramos una espaciosa cabaña, que nos recordaba los ventorrillos Andalucía, y que llaman Bab-el-Uaeli, ó puerta del Valle, donde, verdaderamente cansados, hicimos alto, desmontándonos de los caballos, tomamos sandias y café á la turca, que es todo lo que encontramos en aquel pobre asilo» (III, 80). A lo largo de toda su obra, Rada se preocupa también por relatarnos la situación actual del postrado Oriente (I, 9) y, de esta manera, traza lugares, costumbres, ropajes, objetos, personas del momento de su viaje. Su relato, que alcanza una indudable altura literaria ${ }^{22}$, trata de sumergirnos completamente en el Oriente, que veamos y, además, que escuchemos los sonidos y percibamos los perfumes de cuanto sale a su encuentro. Así, ante nuestros ojos asombrados no sólo se presentan los vestigios procedentes de la Antigüedad y la Edad Media, sino que también desfila el Levante viviente, un universo abigarrado, complejo, que se muestra de manera diferente, y un tanto ilógica e impredecible, para un occidental. El Oriente es distinto, pero, sobre todo, extraño. Finalmente como andaluz de Granada, Rada no deja nunca de señalar las similitudes que observa entre el Oriente y Andalucía.

Pasan después Kariath-el Enab, donde estuvo la bíblica Kariath Yarim (III, 81) ${ }^{23}$. A poco de abandonarla llegan a Castal (III, 81), una fortaleza construida por Vespasiano. Posteriormente, cruzan el torrente Terebinto, donde David cogió las piedras para acabar con Goliath, y se hallaba la antigua Ain $\mathrm{Neftoa}^{24}$. Clareaba ya la albada del día 31 de agosto, cuando los expedicionarios se encontraron con el Cónsul de España en Jerusalén, el Conde de Casa-Sarriá, que venía a recibirlos en compañía del vicecónsul Sr. Espagnolo y de todo el personal de la legación. Tras descansar brevemente, durante una hora, reemprenden el camino de Jerusalén, pasan Colonia ${ }^{25} \mathrm{y}$, a las ocho y media de la mañana, por fin, alcanzan la Puerta de Damasco y entran en la Ciudad Santa, donde son acogidos por el Custodio de Tierra Santa y los Padres del convento de San Salvador. 
Don Juan de Dios de la Rada y Delgado y lo expedicionarios...

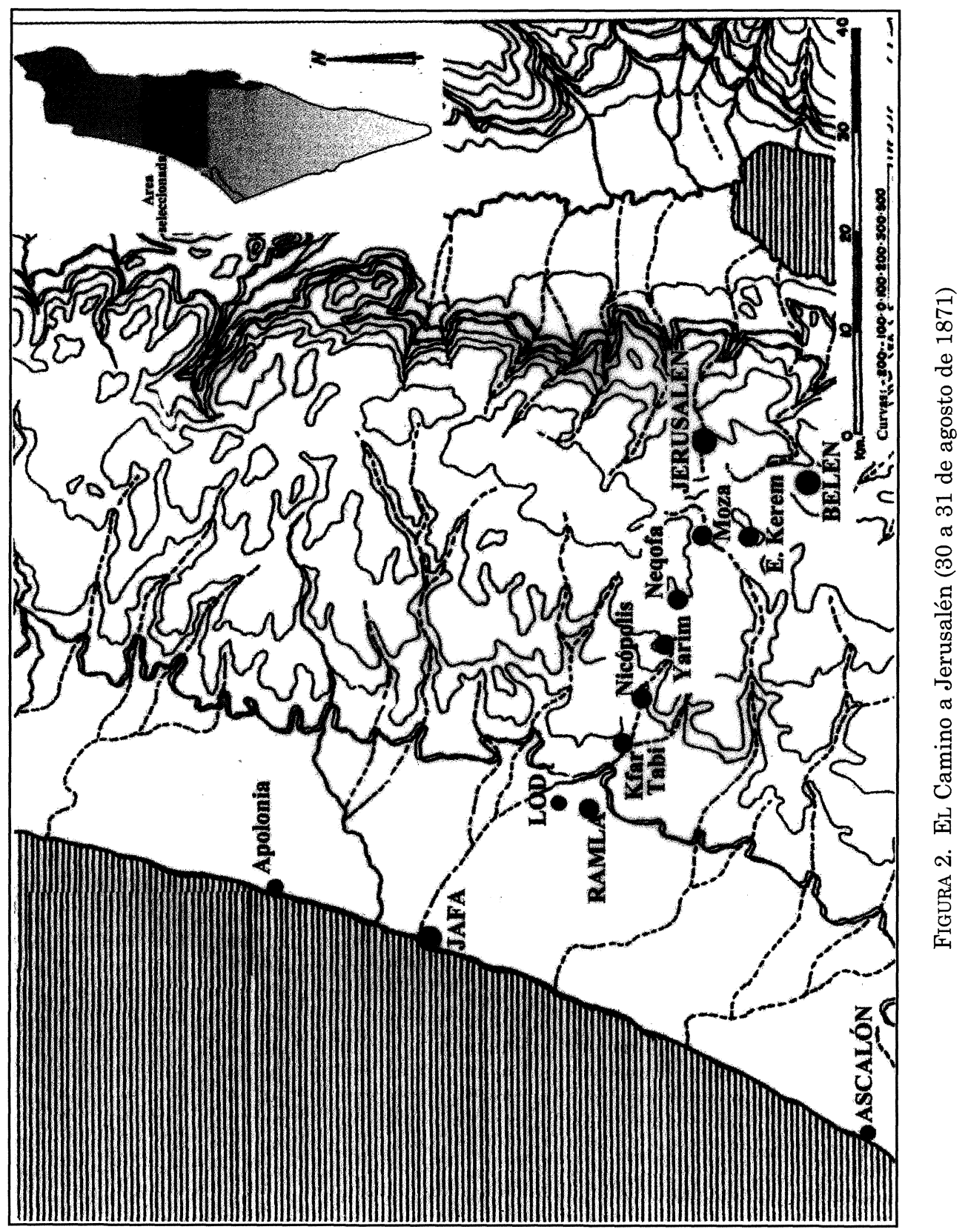




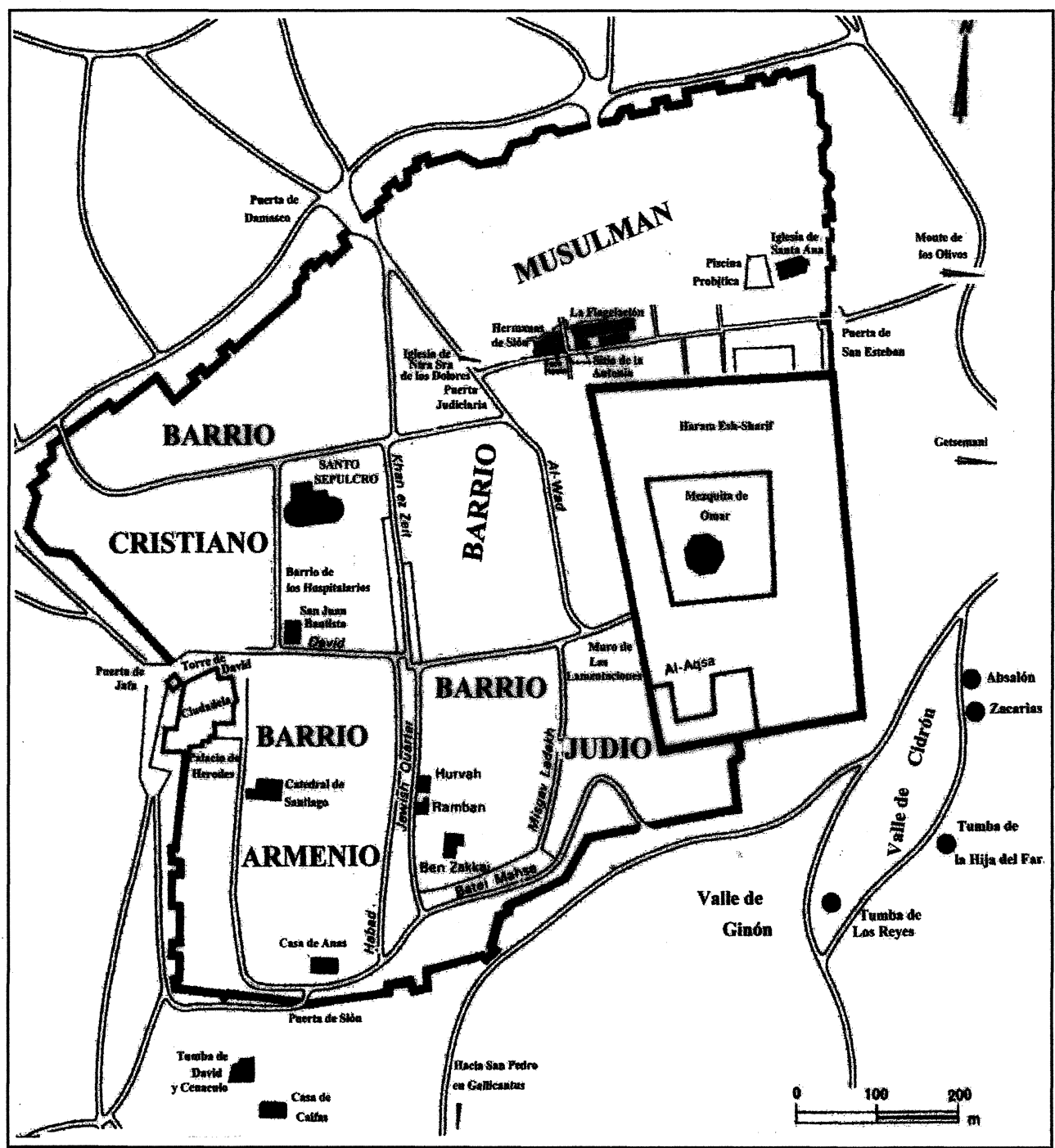

Figura 3. Jerusalén 
Don Juan de Dios de la Rada y Delgado y lo expedicionarios...

A la vista de Jerusalén, Rada entona una suerte de canto a una ciudad que «inspira al alma tal sensación de sublime entusiasmo, que aquella soledad aparece para el creyente poblada de recuerdos inmensos y de eternas esperanzas» (III, 85). Repasa después, de forma breve, la historia de la ciudad, explica su topografía con ayuda de Josefo (III, 86) y señala el estado de abatimiento y ruina en que se encontraba en su época (III, 87).

Ya en Jerusalén, Rada describe en primer lugar la Vía Dolorosa ${ }^{26}$ «siguiendo paso a paso las terribles escenas del inmenso y divino drama de nuestra Redencion, el camino inmortalizado por Jesucristo al dirigirse desde el pretorio de Pilatos hasta el Calvario, cuya distancia es próximamente de un kilómetro" (III, 89). En una forma algo confusa, Rada menciona primero la Puerta de Sión, la Casa de Caifás, lugar de un convento armenio (III, 89) y la capilla del Gallicantus, justo al sur de la ciudad y muy alejadas de la Vía Dolorosa, y luego nos introduce ya en dicha Vía a partir del Arco del Ecce Homo, donde la tradición situaba la primera estación y "sobre el cual según la tradición Pilatos mostró a Jesús al pueblo» (III, 90) ${ }^{27}$, que formaba parte, según Rada, del Pretorio, alguno de cuyos restos pueden verse en el anejo convento de las Hermanas de Sión. Pasa la Iglesia de la Flagelación, de los padres franciscanos, con la Capilla de la Coronación de Espinas, "en el lugar donde los flagrum de los soldados hicieron correr la sangre purísima del Hijo de Dios" (III, 91) y llega al cruce de la Vía Dolorosa con la calle que parte de la Puerta de Damasco, donde se sitúa la Iglesia de Nuestra Señora de los Dolores. Después alcanza las ruinas de la llamada Puerta Judiciaria, donde «no tiene la Vía dolorosa linea fija y demarcada por la tradición» (III, 92) y conjetura "que seguiría derechamente hasta el sitio donde se alzó el redentor suplicio» (III, 92). Rada termina su narración de la Vía Dolorosa con la historia del Calvario. Como podemos observar, en una de las principales características de su narración sobre Tierra Santa, Rada recoge en todos los lugares la tradición cristiana y no sólo la acepta, sin criticarla en ningún momento, sino que, además, sus explicaciones tienden a probar siempre la veracidad de dicha tradición.

El relato de Rada alcanza finalmente el Santo Sepulcro ${ }^{28}$. Como es habitual, Rada procede de manera sistemática describiendo, en primer lugar y de manera bastante exacta, la historia del Santo Sepulcro desde Constantino, la devastación de los persas en 614, la destrucción del califa Al-Hakem en 1009, la posterior reconstrucción, culminada en 1048, y las obras de los cruzados que le dieron su forma definitiva, reuniendo las tres iglesias anteriores, Santo Sepulcro, Calvario e Invención de la Cruz, en una sola. 
Los expedicionarios recorren la compleja iglesia del Santo Sepulcro y escuchan misa en el Edículo del Santo Sepulcro; para Rada es el momento culminante de su visita a Jerusalén ${ }^{29}$, el de la plenitud mística:

"Acabo de llegar de la iglesia del Santo Sepulcro, donde he oido misa, que nos ha dicho el capellan de la fragata, sirviendo de mesa de altar el sepulcro mismo de Nuestro Redentor. Decíros lo que en tales momentos lo que experimenta, es imposible. Sentirse tan cerca del lugar sagrado donde estuvo el Divino Cuerpo del Salvador del mundo; asistir a la misteriosa trasformacion del pan y el vino operada en virtud de las palabras sacramentales del sacerdote, sobre el Santo Sepulcro que encerró en reducido espacio lo que ni en los mundos todos del Universo cabe; [...] verse rodeado de todo lo que recuerda, con la verdad de la historia y de la tradicion no interrumpida, aquel drama divino en que habia de redimirse para el cielo a la mísera humanidad, eran motivos suficientes para que el corazon latiese con emocion profunda y la inteligencia se abismara en las meditaciones de lo infinito, a que naturalmente conduce el espectáculo de la misericordia divina, tomando sobre sí las culpas todas de la humanidad ingrata. En aquellos momentos mi alma no pertenecía a este mundo» (III, 88-89).

Dentro de la iglesia del Santo Sepulcro, en repetidas ocasiones, Rada critica la restauración de los griegos, llevada a cabo entre 1808 y 1810 , que son llamados o no unidos o, sobre todo, cismáticos, que tuvo una doble característica: el mal gusto y «la intención de borrar sistemáticamente cualquier signo de latinidad» (III, 90, 103). Y, también, en todo momento, Rada apoya la tradición cristiana.

El ferviente catolicismo de Rada se refleja, a lo largo de su relato en muchos aspectos; en primer lugar, en la propia vivencia interior de Rada que llega muchas veces al misticismo, y, además, en la aceptación de la veracidad histórica de la tradición cristiana. Desde sus profundas convicciones católicas, otras religiones $\mathrm{u}$ otras divisiones del Cristianismo hallan poca comprensión. Los ortodoxos, a los que llama griegos cismáticos, se ven envueltos en una atmósfera de secta, de ritos semiocultos e incomprensibles y les reprocha su combate contra los católicos. Los musulmanes son igualmente fanáticos y sectarios, sus estructuras son despóticas y sus creencias convierten en sensualismo y materialismo las puras esencias cristianas y llevan a la barbarie y la poligamia. Por último, sobre los judíos sigue cayendo la acusación de haber causado la muerte de Jesucristo y revela el ambiente europeo antisemita de la época que habría de estallar, una vez más poco después, en terribles pogromos como el de 1881 en Rusia. 
Este cristianismo militante condiciona la propia concepción histórica de Rada. De este modo, la evolución histórica está marcada por una sucesión de culturas y civilizaciones, hasta que «la cruz divina divide en dos el mundo de la historia» estableciendo «la sociedad cristiana, deista, contemplati$v a$, mística, rica en ciencia humano» (I, 23). En su pensamiento la historia es, por tanto, fruto de plan divino y adquiere un sentido providencial, que culminará en la siguiente etapa con el establecimiento de la fraternidad universal, esto es, la reunión de la Humanidad bajo la palabra evangélica, universal, del Cristianismo: «un día en que se realice el gran deseo de unidad humana, formando una inmensa familia con un solo padre que es Dios, pensamiento que sólo está llamado a realizar la Religión cristianco (I, 9). Si en lo económico Rada se nos muestra liberal, en lo moral y religioso, expone un conservadurismo muy acusado que inserta y une los valores propios de la burguesía de su tiempo, como son el cumplimiento del deber, la confianza ilimitada en los progresos del saber y la bondad de la ciencia y la técnica, en el pensamiento cristiano: "La religion y el deber son las dos grandes ideas sobre que gira la felicidad individual o colectiva del hombre» $(\mathrm{I}, 25) \mathrm{y}$ : «aquellas benditas hermanas (ciencia, arte e industria), que Dios dejó en el mundo para que engrandecieran al hombre» (I.25). Es precisamente el Cristianismo el que concilia liberalismo y moral, igualdad y progreso y supone la síntesis y solución a todas las contradicciones.

Tras el relato de su visita a la Basílica del Santo Sepulcro, Rada nos anuncia su intención de no detenerse en ir examinando más iglesias (III, 109) y, a partir de aquí, resulta más difícil seguir su exposición. Parece haberse dirigido hacia la Puerta de Jafa, en el sudoeste, donde señala la llamada torre de David y el lugar del antiguo Palacio de Herodes. Después recorre el barrio armenio, al sur, con la catedral de Santiago, donde destaca los vínculos con España, y quizá saliera por la Puerta de Sión ya que menciona la Tumba de David y el Cenáculo, ambos en el mismo edificio, y la gruta de San Pedro, en la vertiente SE del Monte Sión. Pero, después, nos introduce la iglesia de San Juan Bautista, y la explanada donde estuvo el convento de los caballeros hospitalarios de San Juan (III, 109-112), justo al sur del santo Sepulcro y dentro de la ciudad. Vuelve luego al principio de la Vía Dolorosa donde nombra la Iglesia de Santa Ana y la Piscina Probática o de Bethesda (III, 114-115), que pudo visitar quizá al día siguiente, 1 de septiembre; en todo caso, Rada hace comenzar aquí la siguiente fase de su estancia en Jerusalén, la visita al Valle de las tumbas y, desde este punto, su relato puede seguirse con facilidad hasta le final de su estancia en Tierra Santa. Los expedicionarios salen de la ciudad por la Puerta de San Esteban y se dirigen al Valle de Josafat, al sur del cual corre el torrente Cedrón (III, 115). Con el li- 
bro de Saulcy ${ }^{30}$ en sus manos, Rada describe las tumbas más importantes y su relato se convierte en respaldo absoluto de las opiniones de Saulcy. Acuden primero a la Tumba de los Reyes (III, 117-126), aceptando «el parecer de $M$. de Saulcy, que resueltamente admite perteneció en efecto, a lo antiguos reyes de Judón, entre los siglos X y VI. En realidad está ante la tumba de la reina de Adiabene, de mediados del siglo I d.C. Luego se dirigen a la de Santiago el Menor o del Faraón, donde copia una inscripción que traducirá el Padre Fita (III, 126), del siglo I a.C., y a la Tumba de los Jueces, a un kilómetro al NO de Jerusalén, al principio del valle de Josafat (III, 131). Sigue después la llamada Tumba de los Profetas (III, 131), del siglo I a.C., y las tumbas del valle de Ginón (III, 133). Entre los monumentos funerarios exentos describe la Tumba de Absalon que, siguiendo a Saulcy, atribuye efectivamente, a Absalón, hijo del rey David, en realidad es del siglo I d.C. y finalmente, visita la Tumba de Zacarías o de la Mujer del Faraón y que, según Rada, muestra la misma mezcla de elementos arquitectónicos griegos y egipcios de la Tumba de Absalón (III, 138). Dicha tumba se fecha en el siglo II a.C.

$\mathrm{Su}$ relato, con la minuciosidad que le caracteriza, cae, a veces, en la erudición. Y es que en el período en que escribe Rada, entre 1871 y 1876, nos encontrábamos en un momento fundamental de la investigación histórica, marcado precisamente por la transición de la erudición al positivismo científico y Rada da muestras de ambas cosas, de erudición y de positivismo. Así, en ocasiones hace alarde de erudición, carente de todo sentido crítico, con prolijas explicaciones, escasa investigación metódica y ningún análisis de fuentes. Ello es especialmente grave porque en su obra, debido en buena medida a la falta de tiempo, hay más de trabajo de gabinete, de dependencia de sus fuentes, que de indagación y discusión originales. En otras ocasiones se muestra algo inconsistente y no es fácil conocer los lugares que efectivamente visitó ni su ruta por la Ciudad Santa. Su concepción arqueológica está inmersa todavía en el coleccionismo y el anticuarismo, en la acumulación de objetos descontextualizados, sin método, la mayor parte de las veces por puro esteticismo, por una visión estética de búsqueda de obras bellas. Pero también nos devuelve un incipiente positivismo; de esta manera, Rada se desprende de los relatos de viajes que introducen narraciones inverosímiles, hazañas, peligros y aventuras y en todo momento trata de construir un exposición verosímil, adopta un actitud empírica y una mentalidad científica, que propugna la utilidad del examen in situ con ayuda de planos y dibujos, y desarrolla un método que comienza a ser sistemático, fundado sobre una cronología exacta.

Tras la visita al Valle de las Tumbas, se dirigen a la explanada del templo, Haram esh-Sherif, donde Rada enumera minuciosamente las 
diez puertas y las construcciones que rodean el recinto (III, 149). En el caso de la explanada es la única vez, y de forma tangencial, que Rada se refiere a "las investigaciones y sondajes de los oficiales de ingenieros de la armada inglesa encargados de explorar Palestina» (III, 148). Describe la disposición general en cuadrilátero del monte Moriah y la mezquita de Omar, cuya planta, un octógono regular inscrito en un círculo de veintisiete metros de diámetro, le sirve para probar el bizantinismo del arte islámico "este monumento bizantino, así en su disposición como en sus detalles, recuerda, por su forma las construcciones poligonales y circulares levantadas por los cristianos en los primeros siglos de la iglesia» (III, 149), y termina con la narración de la mezquita de El Aqsa (III, 152).

Ese mismo día, primero de septiembre de 1871, los expedicionarios salen a las tres y media de la tarde, bajo un sol ardiente, por la Puerta de Jafa, para recorrer los nueve kilómetros que separan Jerusalén de Belén. Como dice el propio Rada, se trataba de una «peregrinación tan conmovedora» (III, 158) en la que les acompaña un franciscano español, el P. Francisco, que habría de morir pocos años después en unos disturbios protagonizados por musulmanes. Si Rada siente un profundo respeto por los sacerdotes y misioneros de Tierra Santa, en el caso del Padre Francisco, se llega al ejemplo sublime de quien: "puesta en Dios la mira y olvidándose del mundo y de si mismo, piensa únicamente en la redención de las almas, arrancándolas de las tinieblas de la barbarie, y abriéndoles los hermosos y fecundos caminos de la civilización cristiana en la tierra, y la vida de la inmortalidad en el cielo» (III, 158). Rada evoca en el P. Francisco a Pedro el Ermitaño y los expedicionarios se sienten auténticos cruzados (III, 159).

El trayecto despierta en los viajeros, nuevamente, los recuerdos bíblicos, el camino que pisaron Jacob y David, los Magos, La Virgen, San José y el Salvador. Así, llegaron al lugar del Reposo de la Virgen o Cathisma ${ }^{31}$ y pasaron el monasterio griego de San Elías. Alcanzaron luego el llamado sepulcro de Raquel y entraron poco después en Belén ${ }^{32}$.

A Rada, Belén le evoca a su Andalucía, "la pequeña ciudad de Judea asentada en una altura y esparcida por la accidentada vertiente de una montaña, con sus casas blancas y sus terrados como los de mi inolvidable Almería, allá en las orillas opuestas del Mediterráneo. Alli está aquel pueblo con que soñé desde niño, y que, cosa extraña, no me pareció desconocido, porque su aspecto era el mismo de los tradicionales Nacimientos de mi católica patria» (III, 160). Al entrar en la ciudad los viajeros sienten la expansión psicológica, la alegría de encontrarse en una ciudad mayoritariamente cristiana: «nuevas y gratas emociones conmovieron mi corazon. Los habitantes de ella, léjos de ofrecernos las impasibles ó desdeñosas fiso- 


\section{José Pascual González}

nomias de los musulmanes, nos miraban con cariñosa solicitud, y hermosas muchachas, con el rostro descubierto, nos ofrecían en limpios canastillos los frutos de sus huertos. Había desaparecido el seco y suspicaz carácter turco. Estábamos entre cristianos» (III, 162). Como cristianos, los belenitas son industriosos y deben su prosperidad a la agricultura y la ganadería, a los muros, "como las paratas de nuestras montañas granadinas" (III, 161), que desvían las torrenteras de las montañas y a la artesanía de recuerdos para los peregrinos que visitan la Basílica de la Natividad. Esta imagen no deja de ser fascinante porque en ella se aúnan la Belén real de 1871 y la Belén que debiera ser en la mente de nuestros expedicionarios este es, la Belén de los belenes españoles.

Rada narra primero la historia de la Basílica de la Natividad ${ }^{33}$. En la Gruta de la Natividad, Rada hace una encendida defensa de la tradición afirmando que "ningún lugar existe en la tierra cuya identidad esté mejor probada que la Gruta de Belén [...] el venerado sitio donde nació el Salvador» y hace profesión de fe en "mística contemplación del inmenso misterio de amor divino, alli realizado hace diez y nueve siglos». Rada inspecciona luego las diferentes capillas subterráneas y examina la propia Basílica señalando el triste estado en que se encuentra, un templo «hoy profanado, invadido por mercaderes y por turcos que se pasean por él fumando sus pipas» mientras "los griegos cismáticos apoderados del edificio, los cuales para las necesidades de su culto, se han contentado con cerrar parte del crucero, adornándole para celebrar sus oficios", y se queja de que "Allí como en tantos otros lugares de la Palestina, los católicos son los únicos que no tienen autorización para erigir altares». Por último, visitan la llamada Gruta de la leche y la Gruta de los pastores donde, como es habitual, Rada sostiene una fe en la tradición sin asomo de duda o crítica.

Por la noche nuestros expedicionarios regresan a Jerusalén. Al día siguiente, viernes 2 de septiembre de 1871, Rada y los demás miembros de la expedición se dirigen a ver el Llanto de los Judíos sobre el Muro de las Lamentaciones, donde Rada expresa un antisemitismo cristiano muy propio de la época: "aquel pueblo Deicida en su inmensa e indescriptible pena, que les lleva de nacion en nacion y de siglo en siglo errantes y sin patria, a pesar de las inmensas riquezas que su codicia consigue acumular en determinadas familias, como viviente testimonio de las narraciones evangélicas, derramando amargas lágrimas en los mismos lugares donde crucificaron cruelmente al Hijo de Dios, que descendió a la tierra para salvarles» (III, 170) ${ }^{34}$.

Ese mismo día parten para Jafa, a través de la Puerta homónima, camino del monasterio de San Juan del Desierto, a unos siete kilómetros al oeste de Jerusalén, localizado junto a la aldea del mismo nombre ${ }^{35}$. Aquí 
hicieron un alto, durante un par de horas, en el convento de los Padres de Tierra Santa, cuyo Superior era español y malagueño. Después reanudaron la marcha; pero, sin guías y en plena noche, se extraviaron de regreso a Ramla: «emprendimos de nuevo el camino a Jafa, sufriendo en aquella noche no pocas penalidades por habernos perdido en medio de barrancos casi intransitables, y habernos visto a punto de caer en manos de beduinos. Cerca del día tuvimos al fin la fortuna de llegar, molidos y con las ropas destrozadas, al convento de Ramla, y después de descansar algunas horas, emprendimos de nuevo el camino a Jafa, donde llegamos cerca de las doce de la mañana, habiendo sufrido en las tristes llanuras que viniendo de Jerusalén preceden a Jafa, terribles momentos de sed $y$ de calor» (III, 175). Es posible que, tras visitar San Juan del Desierto, los expedicionarios trataran de tomar nuevamente la vía que les había traído a Jerusalén pero, sea como fuere, anduvieron vagando al sur de dicha ruta, en torno a la actual carretera $\mathrm{n}^{\circ} 395$, un camino difícil a través de las montañas de Judea en el que sufrieron bastantes penalidades.

A las cinco de la tarde del 3 de septiembre, la fragata abandonó la rada de Jaffa en demanda de Port Said, dejando atrás Palestina. Hacia las cinco de la tarde del día 4 los expedicionarios fondearon en la rada de Port Said (III, 179), de donde levaron anclas el 5 arribando el 7 de septiembre en Alejandría (Tudela, 1873, 45). Desde Alejandría alcanzaron Malta el día 15 de donde parten el 16 para llegar, finalmente, a Cartagena el 22 de septiembre de 1871, dando término, así, a un viaje que fue, y sigue siendo, extraordinario y fascinante.

\section{Notas}

1 Amadeo I de Saboya (1845-1890), tercer hijo del rey de Italia Víctor Manuel II, fue elegido rey de España por las Cortes en la sesión del 16 de noviembre de 1870. Llegó a Madrid el 2 de enero de 1871 y formó su primer gobierno el 4 de enero de 1871 . Abdicó el 10 de febrero de 1873. Véase: BoLAÑos MEJíAS, C. (1999): El reinado de Amadeo de Saboya y la monarquía constitucional, Madrid y OLLERO VALLÉS, J.L. (2000): «Triunfo y disolución del progresismo, 1868-1874» en A.A.V.V. Sagasta y el liberalismo español, Madrid, 294-301.

2 Carta del Vicepresidente de la Secretaría del Almirantazgo al Comandante de la fragata de 10 de junio de 1871 (Archivo Nacional «Álvaro Bazán» leg. 1176/59; abreviado ANAB).

3 D. Juan de Dios de la Rada y Delgado era natural de Granada donde había nacido en 1827. De la Rada ya había participado en varias comisiones arqueológicas que recorrieron España con la intención de recoger piezas para los fondos del Museo, tenemos anotadas al menos dos, una a las provincias del Norte en 1869 y otra en el Sur peninsular en el año siguiente. Es Oficial del Cuerpo de Bibliotecarios, Archiveros y Anticuarios en 1867. En 1869 era Jefe de Tercer Grado, el tercero en el escalafón, del M.A.N. puesto 
que ocupa en el momento de la expedición. Tendría una brillante carrera posterior. En 1873 es Jefe de Segundo Grado y, desde 1881, compatibiliza su dedicación en el M.A.N. con la Escuela de Diplomática de la que es profesor. En 1883 es catedrático de la Escuela Diplomática, de la que será Director, en 1892 es Inspector Segundo del Cuerpo de Archiveros, Bibliotecarios y Anticuarios y, entre 1891 y 1900, es Director del MAN. Fue también Director del Museo Español de Antigüedades y académico de la Historia. Falleció en 1901 siendo Director del Museo de Reproducciones artísticas (Archivo del M.A.N. Exp. 1871/58 y Expediente personal de D. Juan de Dios de la Rada, abreviado AMAN).

4 RADA y DELGADO, J. de D. (1876): Viaje a Oriente de la Fragata "Arapiles" y de la comisión científica que llevó a su bordo, Barcelona, 3 vols. Contamos además con las siguientes publicaciones: GARCíA de TUDELA, I. (1873): Anuario del Depósito Hidrográfico, 1 y ss.; Estrada CATOIRA, R. (1923), «Recuerdos de un tiempo viejo», Rev. General de la Marina, 447-467 (en 1871, Estrada es guardia marina a bordo de la Arapiles); MoRENo de la TEJera, V. (s.f.): Diario de un viaje a Oriente, Argel, Nápoles, Pompeya y el Vesubio, Sicilia, Grecia, el Archipiélago, Turquía y Egipto. Viaje verificado ábordo de la fragata de guerra "Arapiles", Madrid (Moreno de la Tejera es el médico de la fragata). A todo ello hay que sumar los documentos conservados en los archivos de la Marina (ANAB, Leg. 1176/59) y del Museo Arqueológico Nacional (AMAN, exp. 1871/58 y expediente personal de J. de Dios de la Rada y Delgado). Sobre el viaje en su conjunto véase CHINCHILLA, M. (1993): «El viaje a Oriente de la fragata Arapiles» en A. Marcos Pous (comp.), De Gabinete a Museo. Tres siglos de historia, Madrid, 286-300.

5 Falleció al año siguiente siendo Secretario de la Embajada española en Constantinopla, posiblemente víctima del cólera.

6 Falleció en 1923, ocupando el cargo de arquitecto y académico de la Real Academia de San Fernando.

7 Capítulo 20 del presupuesto del Ministerio de la Gobernación por ley de 25 de junio (carta de Juan Valera de fecha 13 de junio de 1871, AMAN).

8 Carta del Comandante al Ministro de Marina en Chanak, en los Dardanelos (ANAB). 95,15 pesetas equivalían en 1871 a 100 francos cf. CARRERAS, A. (1989) (coord.): Estadísticas históricas de España siglos $X I X-X X$, Fundación Banco Exterior, Madrid.

9 El Comandante pasa también por numerosos apuros económicos. Antes de la partida, el propio Almirantazgo español ordena al Comandante de la fragata que la nave no se detenga más de cinco días en ningún puerto y le encarece que «la economía del erario y la instrucción marinera de sus subordinados objeto siempre de preferente atención exigen el empleo del aparejo exclusivamente siempre que las circunstancias lo permitan" (ANAB). A lo largo del viaje el Comandante solicita fondos continuamente al Ministerio de Marina y recibe nuevos créditos en Nápoles y en Constantinopla.

${ }^{10}$ A pesar de todo ingresan en el MAN veintidós cajones con trescientos veintinueve objetos procedentes de donativos (RoDRÍGUEZ VILLA, A. (1871) «Adquisiciones del Museo Arqueológico Nacional», RABM, 262-266).

11 Idem TUDELA 1873, 44, 55.

12 TsafRIR, Y. (1994): Tabula Imperii Romani. Iudaea-Palaestina. Eretz Israel in the Hellenistic, Roman and Byzantine periods, mapas and gazetteer, Jerusalén, 152-153, abreviado TIR; KAPLAN, H. y J. (1977), en M. Avi-Yonah (ed.), Encyclopedia of archaeological excavations in the Holy Land, vol. III, Oxford, 532-541, abreviado Encyclopedia. Tel Aviv surgirá aquí en 1909.

13 Moreno de Tejera, s.f., 248 y Tudela, 1873, 38. 
14 Como señala Rada, el camino cuenta con diecisiete torres de vigilancia construidas desde 1860 (III, 74). El viaje de ida a Jerusalén se realiza sin contratiempos.

15 Cada legua equivale a 5.572 metros con diez decímetros. La distancia actual entre Jaffa y Jerusalén, vía Ramla, es de 81 kilómetros.

${ }_{16}$ Kfar Tabi, quizá la antigua Enetaba (SAUlcy, F. de, 1872: Voyage en Terre Sainte, I, París, 80-81; TIR 166).

17 Gat no estaba situada en Ramla sino en el extremo de la llanura de Sarón, en el camino antiguo de Eleuterópolis y Gaza (TIR 134).

18 Erróneamente Rada identifica, sobre la base únicamente de la similitud de los nombres, Ramla con Ramathaim-Remphthis o Arimatea que se encontraba, en realidad, al sur de Judea, en Samaria (TIR 67; RosEN-AYALON, M. 1978, «Ramla» Encyclopedia, IV, 1010-1014).

19 Qobi o Qobia (GUÉRIN, V. 1868-1869, Description géographique, historique et archéologique de la Palestine: Judée, vol. II, París, 384-385; TIR 209).

20 Situada a unos quince kilómetros al sudeste de Lod (GUÉRIN, Judée, I, 285-290, TIR 88).

21 Es el lugar de la victoria de Judas Macabeo sobre los seléucidas en 161 a.C. (1 Macc. 3.38-4, 15); en 221, Heliogábało le otorgó el nombre de Nicópolis y fue sede episcopal en el siglo IV. El asentamiento está compuesto por una acrópolis, donde se elevó mucho después una iglesia cruzada y una fortaleza en el camino de Jerusalén, y la ciudad baja que hoy en día ocupa el sitio del llamado Parque de Canadá (MURPHY-O'ConNoR, J. 1980, The Holy Land. An Archaeological Guide from Earliest Times to 1700, Oxford, 233, abreviado Holy Land). Es el lugar tradicional de la aparición de Jesús a Cleofás (Luc.24.13). Vid. también Saulcy, 172-172; GUÉRIN Judée, I, 293, 308; AvI-YoNAH, M. 1976, «Emmaus» Encyclopedia, III, 362-362; TIR 118-119).

${ }^{22}$ LITVAK, L. (1987), El ajedrez de las estrellas. Crónicas de viajeros españoles del siglo XIX por países exóticos (1800-1913), Barcelona, 219-220, 228-229.

${ }^{23}$ Qiryat Yarim se localiza en Deir el Azhar, cerca de Abu Gosh, a unos dieciocho kilómetros de Jerusalén (GUÉRIN, Judée, 62-71; TIR 100).

24 Acerca del torrente Terebinto o Namre: APPELBAUM, S. 1977, Encyclopedia III, 776-778.

25 Fue fundada por Vespasiano como colonia militar, ahora es Moza (Holy Land 235; TIR 105).

${ }^{26}$ La Vía Dolorosa ha sido establecida por la fe y poco tiene que ver con la historia. En realidad, es bastante probable que Jesús fuera condenado a muerte en el otro lado de la ciudad, en la Ciudadela, donde se localizaba el Palacio de Herodes y el lugar en el que residía Pilatos cuando venía desde Cesarea (Filón. Delegación a Gayo. 38). La ruta verdadera debió ir hacia el este de la actual calle de David, pasaría al norte del triple zoco y alcanzaría el Gólgota por el oeste (Holy Land, 25).

27 Sobre Jerusalén A.A.V.V. «Jerusalem», 1976, Encyclopedia, III, 579-647; TIR 145146 y Navigad, N. (1984), Discovering Jerusalem. Oxford. Se pensaba que el Arco del Ecce Homo formaba parte de la Fortaleza Antonia, construida por Herodes entre 35 y 37 d.C., el arco estaría en la entrada y el pavimento era el patio. Sin embargo, las excavaciones sugieren que el pavimento era el Foro de Adriano y el arco formaba parte de la Puerta Oriental de Elia Capitolina (Holy Land 24).

28 Probablemente, en efecto, Jesús muriera en este lugar, o por lo menos lo que conocemos de la topografía de la ciudad y del registro arqueológico es compatible con la narración evangélica. De hecho, el lugar que hoy ocupa el Santo Sepulcro se hallaba fuera 


\section{José Pascual González}

de los muros, existía aquí una cantera abandonada en el siglo I y hay tumbas de este período (Juan.19.17, 41-42, Holy Land, 36-37).

29 Rada piensa en una tumba piramidal, separada del Calvario por Santa Helena (III, 97), pero, en realidad la tumba de Jesús sería de cámara excavada en la roca (kohim), característica de los cementerios judíos del siglo I.

${ }^{30}$ SAULCY F. de (1858), Histoire de l'art judä̈que: tirée des Textes Sacrés et Profanes, París.

31 Donde existe una iglesia octogonal y un monasterio (TIR 101).

32 Sobre Belén: STELEKIS, M., AVI-YonAH, M. 1973, Encyclopedia, I, 198-206; TIR 83.

${ }^{33}$ Las identificaciones no tienen valor histórico (cf. AvI-YoNAH, M. 1975, Encyclopedia, I. 200-201, Holy Land 146-148).

34 Rada muestra, en general, poco interés por el Judaísmo, de hecho, no visitó el Barrio judío a pesar de que éste contaba con un buen número de importantes sinagogas como las de Ramban y Hurva y las cuatro sefardíes.

${ }^{35}$ S. Juan del Desierto es la antigua Ein Karem o Beth Ha-Kerem (Encyclopedia I 304-305; SALleR, S.J., 1946, Discoveries at St. John's, Ein Karim, 1941-1942, Jerusalén; TIR 82). 